\title{
INDOOR CORROSIVITY IN KLEMENTINUM BAROQUE LIBRARY HALL, PRAGUE
}

\author{
KATERINA KREISLOVA ${ }^{1}$, PAVLINA FIALOVA ${ }^{1} \&$ TEREZA BOHACKOVA $^{2}$ \\ ${ }^{1}$ SVUOM Ltd., Czech Republic \\ ${ }^{2}$ VSCHT, Czech Republic
}

\begin{abstract}
Air pollution in museums, libraries, churches, and other indoor environments of culture heritage objects was studied since 1980s. For classification of corrosivity of such type of indoor environments the ISO 11844 series was developed. The indoor corrosivity for basic metallic materials had been studied for Baroque library hall of Klementinum areal, Prague, using exposure of metallic coupons and measuring the climatic and pollution parameters. The Baroque library was first opened in 1722 year as a part of the Jesuit university based in Klementinum. It houses over 20,000 books, from the beginning of the 17th century until recent times. As the building is located in the centre of Prague, the outdoor environment is polluted mainly by nitrogen oxides from traffic source, but in 1990s of last century the sulphur dioxide pollution was also on high level. The Baroque hall is cladded by wooden panels which maybe a source of vapour organic acids corrosive for some metals and other materials as fresco paintings. The indoor gaseous air pollution was measured for 2 years with passive samplers $-\mathrm{SO}_{2}$, $\mathrm{NO}_{\mathrm{x}}$, vapour acetic acid. The new method for acetic acid measurement was verified. Metallic coupons of zinc, coper, silver and lead were exposed in this hall for one year and their mass increases and corrosion mass losses were evaluated. For metallic coupons the colour change is one of measured parameters, too. Repeated one-year measurement data are presented and indoor corrosivity according to ISO 11844 was determined.
\end{abstract}

Keywords: indoor corrosivity, air pollution measurement, organic acid vapours, metallic coupons corrosion loss.

\section{INTRODUCTION}

The large complex of Klementinum was founded by the Jesuits after their arrival in Bohemia in 1556 year. Initially, members of the order lived in a former Dominican monastery, but in 1653 year began expanding their premises. The reconstruction lasted over 170 years, so there is a variety of architectural styles in Klementinum. With more than 2 hectares it is also one of the largest building complexes in Europe and a part of Prague UNESCO cultural heritage.

The Baroque library was first opened in 1722 year as a part of the Jesuit university based in Klementinum (Fig. 1). The interior of the Baroque library has remained intact since the 18 th century. The library currently contains a number of important and unique works, that have global significance. It houses over 20,000 volumes of mostly foreign theological literature, coming into Klementinum from the beginning of the 17th century until recent times. Books with white painted spines and red marks have been in the library since the time of the Jesuits.

As the building is located in the centre of Prague, the outdoor environment is polluted mainly by traffic source, but in 1990s of last century the sulphur dioxide pollution was also on high level. Both these air pollutions affected the indoor environment. Presented article gives the new results about the characterisation of indoor atmospheric corrosivity in Baroque library hall. The climatic parameters and air pollution were measured for long period and show the effect of changing outdoor air pollution onto their indoor level.

The Baroque hall is cladded by wooden panels and equipped by wooden bookcases which maybe a source of vapour organic acids corrosive for some metals used in historic books as 
decoration and painting pigments and mainly the paper itself. The specific pollution by organic vapour acids (formic, acetic) was measured together with metallic coupons exposure to determinate indoor corrosivity. Repeated one-year measurement data are presented and indoor corrosivity according to ISO 11844 was determined.

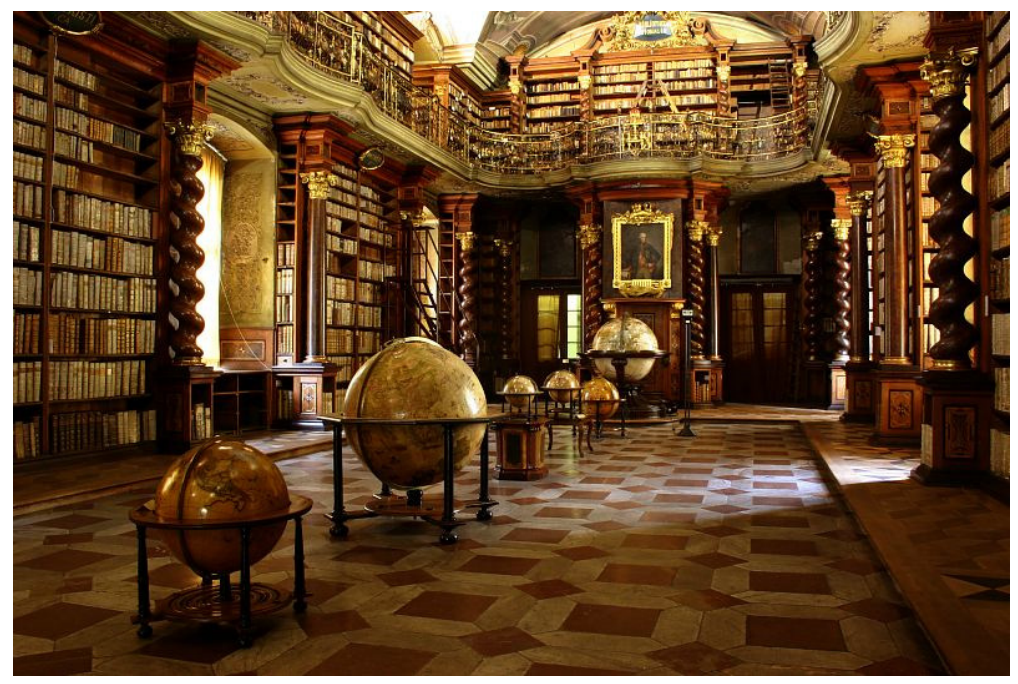

Figure 1: Klementinum Baroque library hall.

\section{METHODOLOGY OF INDOOR CLASSIFICATION}

Air pollution in museums, libraries, churches, and other indoor environments of culture heritage objects was studied since 1980s [1], [2]. One significant source was outdoor air pollution, mainly by $\mathrm{SO}_{2}$ and $\mathrm{NO}_{x}$, which concentration decreased according to distance of outdoor source and type of building. Contemporary outdoor air pollution situation in Europe has not significant effect on indoor environments. For classification of indoor environments corrosivity of storage rooms, museums and churches the ISO 11844 Corrosion of metals and alloys - Classification of low corrosivity of indoor atmospheres series was developed. The evaluation of low-corrosivity indoor atmospheres can be accomplished by direct determination of corrosion attack of selected metals (see ISO 11844-2) or by measurement of environmental parameters (see ISO 11844-3) which may cause corrosion on metals and alloys. This classification and mainly the methods for determination and/or estimation of indoor corrosivity had been applied in many cultural objects [3]-[7].

The determination of corrosivity of indoor atmospheres is based on measurements of corrosion attack on triplicate standard specimens of five reference metals (carbon steel, zinc, copper, silver, lead) after their exposure for one year. In 2020 the revision of this ISO 11844 series had been finished, where lead was included as standard specimen with high sensitivity to vapour organic acids. Rectangular coupons in the form of flat sheets shall be exposed vertically.

Environmental characteristics are informative and allow assessment of specific corrosion effects with regard to individual metals. Corrosion for many of the metals is significantly influenced by the synergistic effects of different pollutants. Due to the permanent exchange between indoor and outdoor air caused by infiltration and ventilation processes, it may be important to supplement indoor air measurements with a simultaneous measurement of the 
outdoor air. For $\mathrm{SO}_{2}$ and $\mathrm{NO}_{\mathrm{x}}$ the passive sampling was used on the monthly basis for longterm period at outdoor environment and in indoor environment (Baroque library hall). The model estimates the indoor concentration of pollutants originating from outdoors was derived for the steady-state indoor/outdoor ( $\mathrm{I} / \mathrm{O}$ ) relation as 0.5 for sulphur dioxide and 0.6 to 0.8 for nitrogen oxides.

But indoor environments are sources of specific type of pollution themselves. Especially applied materials for construction of showcases are potential emission source for variety of volatile organic compounds [8], [9]. Formaldehyde, formic and acetic acids belong to the most discussed pollutants in the museum and similar environments. Their corrosion impact increases in the following order: formaldehyde $<$ formic acid $<$ acetic acid. The active sampling and long-term passive sampling were used for acetic acid measurement in Baroque library hall.

\section{MEASURED ENVIRONMENTAL AND CORROSION DATA}

\subsection{Environmental data at Baroque hall}

The Baroque library hall is not heated space, but other part of building is heated. Climatic data in library were measured in hours intervals. Temperature was in range $11^{\circ} \mathrm{C}$ to $26^{\circ} \mathrm{C}$ and relative humidity in range $37 \%$ to $62 \%$ (Table 1). The corrosion level can be expected to increase for each $10 \%$ rise in $\mathrm{RH}$ above $50 \%$, and also for each rate of change of $\mathrm{RH}$ greater than $6 \%$ per hour. In Table 1 the climatic data are summarised and classified levels are indicated.

Table 1: Summarising of environmental parameters in Baroque hall.

\begin{tabular}{|l|c|c|c|c|c|}
\hline \multirow{2}{*}{ Level } & \multirow{2}{*}{$\begin{array}{c}\text { Temperature } \\
\left({ }^{\circ} \mathrm{C}\right)\end{array}$} & \multirow{2}{*}{$\begin{array}{c}\text { Relative } \\
\text { humidity }(\%)\end{array}$} & \multicolumn{3}{|c|}{$\begin{array}{c}\text { Concentration of gaseous pollutants, } c \\
\left(\mu \mathrm{g} \cdot \mathrm{m}^{-3}\right)\end{array}$} \\
\cline { 4 - 6 } & $\mathrm{T}<15$ & $\mathrm{RH}<40$ & $\mathrm{SO}_{2}$ & $\mathrm{NO}_{\mathrm{x}}$ & $\mathrm{H}_{2} \mathrm{~S}$ \\
\hline I & $15 \leq \mathrm{T}<20$ & $40 \leq \mathrm{RH}<50$ & $1 \leq c<5$ & $1 \leq c<5$ & $c<0.3 \leq c<1.5$ \\
\hline II & $25 \leq \mathrm{T}<30$ & $50 \leq \mathrm{RH}<70$ & $5 \leq c<10$ & $5 \leq c<10$ & $1.5 \leq c<3$ \\
\hline III & $\mathrm{T} \geq 30$ & $\mathrm{RH} \geq 70$ & $c \geq 10$ & $c \geq 10$ & $c \geq 3$ \\
\hline IV & \multicolumn{5}{|c}{} \\
\hline
\end{tabular}

The $\mathrm{SO}_{2}$ air pollution in the centre of Prague was relatively high till 1990s of the last century and then decreased (Fig. 2(a)). The $\mathrm{NO}_{\mathrm{x}}$ air pollution depended on traffic intensity in this locality which decreased with changes in traffic policy and building new roads. Air pollution by $\mathrm{SO}_{2}$ and $\mathrm{NO}_{\mathrm{x}}$ is measured by passive samplers according to ISO 9225 since 2007 in outdoor localities of the Klementinum buildings and in selected indoor localities, including Baroque library hall (Fig. 2(b)). In 2006/07 the $\mathrm{SO}_{2}$ concentration was ca $9.0 \mu \mathrm{g} \cdot \mathrm{m}^{-3}$ at outdoor atmosphere and 3.5 to $4.0 \mu \mathrm{g} \cdot \mathrm{m}^{-3}$ at indoor atmosphere, i.e., ca $40 \%-45 \%$ from outdoor pollution level. Contemporary $\mathrm{SO}_{2}$ at outdoor atmosphere decreased on ca $5 \mu \mathrm{g} \cdot \mathrm{m}^{-3}$ and the pollution level in indoor is on the same level so the $\mathrm{I} / \mathrm{O}$ ration is only 0.8 . Contemporary $\mathrm{NO}_{\mathrm{x}}$ air pollution at outdoor atmosphere is ca $25 \mu \mathrm{g} \cdot \mathrm{m}^{-3}$ and the pollution level in indoor is ca $14 \mu \mathrm{g} \cdot \mathrm{m}^{-3}$ so the $\mathrm{I} / \mathrm{O}$ ration is 0.6 . In Table 1 the pollution data are summarised and classified levels are indicated.

The pollution effect of indoor corrosion is specific for each metal and interdependent (combination of contaminants, humidity and temperature effects). The concentration of all 


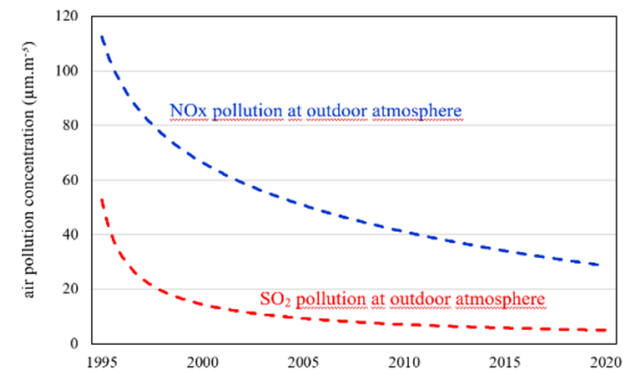

(a)

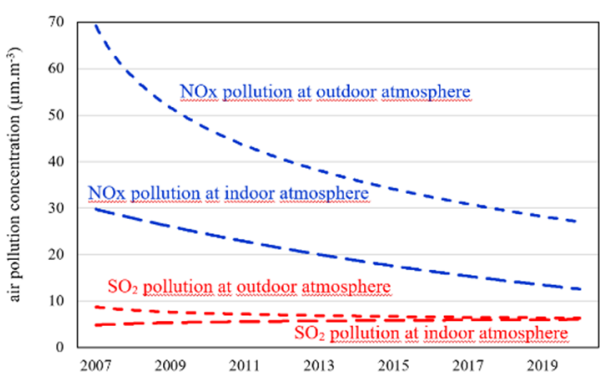

(b)

Figure 2: Trends in air pollution in locality. (a) Long-term trend in outdoor air in Klementinum locality; and (b) Comparison between outdoor and indoor pollution in Klementinum.

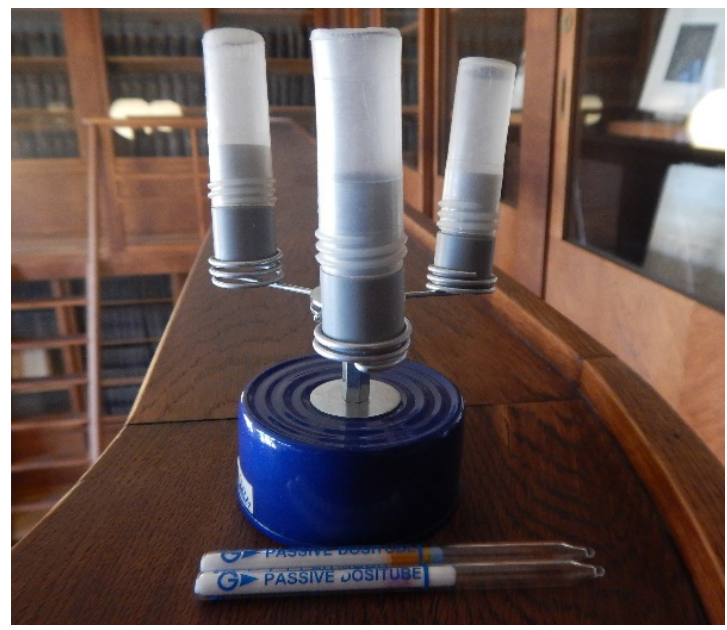

Figure 3: Passive sampling of acetic acid.

measured corrosive gaseous pollution was very low. Only exception is nitrogen oxide which is not so corrosive as other acidic pollution.

The standardised approach does not include concentration of vapour organic acids which are corrosive to metal as zinc and lead. There are no classification levels for organic vapour acids. Formic and acetic acids' concentrations in Baroque library hall were measured by using active and passive sampling by Gastec Dosimeter Tubes. $\mathrm{CH}_{3} \mathrm{COOH}$ concentration was measured as $1,228 \mu \mathrm{g} \cdot \mathrm{m}^{-3}(0.5 \mathrm{ppm} \sim$ lower limit for detection) and HCHO concentration was $377 \mu \mathrm{g} \cdot \mathrm{m}^{-3}(0.2 \mathrm{ppm})$. This method was used for $\mathrm{H}_{2} \mathrm{~S}$ with under lower detection limit $(<0.01 \mathrm{ppm})$.

For more precise and long-term measurement of acetic acid vapour, the passive samplers were used (Fig. 3). Samplers are stainless steel mesh discs in plastic tubes containing $40 \mu 1$ of $1 \mathrm{M}$ potassium hydroxide solution and $10 \%(\mathrm{v} / \mathrm{v})$ ethylene glycol dimethyl ether [10]. After exposure the absorbed acetic acid content is analysed from water extract by ion chromatography method. Based on the obtained mass $m$, known sampling rates $v$ and 
sampling time $t$, the concentration $c$ of analytes in the sampled air in mass per air volume was calculated with equation:

$$
c=\frac{m}{v \times t}
$$

The yearly average of monthly values of vapour acetic acid is ca $280 \mu \mathrm{g} \cdot \mathrm{m}^{-3}(0.11 \mathrm{ppm})$ in Baroque library hall, but it shows very significantly dependence on temperature (Fig. 4). In summer months the average acetic acid concentration was ca $460 \mu \mathrm{g} \cdot \mathrm{m}^{-3}(0.20 \mathrm{ppm})$. During this period the temperature in the Baroque hall was ca $25^{\circ} \mathrm{C}$. In other months when average temperature was $15.5^{\circ} \mathrm{C}$ the acetic acid concentration was $225 \mu \mathrm{g} \cdot \mathrm{m}^{-3}$. Although the wooden cladding and furniture in Baroque hall is created some centuries ago there is still significant source of vapour organic acids. The differentiation of passive measurement of acetic acid by passive tubes exposed only few days in indoor environment and passive samplers exposed for one month gives different values, but passive samplers are more sensitive method.

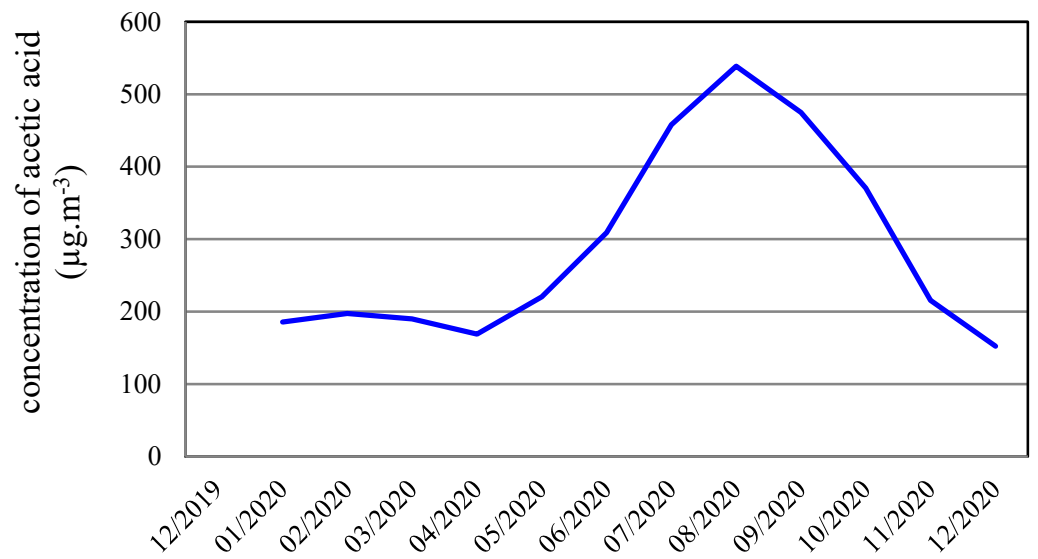

Figure 4: Acetic acid concentration measurement.

\subsection{Corrosion data at Baroque hall}

The metallic coupons (zinc, copper, silver, lead) with dimension $30 \times 80 \mathrm{~mm}$ and $50 \times 50$ $\mathrm{mm}$ were prepared from metallic sheets. The weight loss coupons were abraded with silicon carbide paper to 320 grids, cleaned with de-ionised water, and degreased with ethanol prior to exposure. The triplicate coupons of each metal were exposed vertically mounded on small plastic racks in selected indoor environments for 1 year period (Fig. 5). The coupons designed for electrolytic reduction were polished with P1200 emery paper, rinsed with de-ionised water and degreased with ethanol in ultrasound bath for 5 minutes.

The colour $(\Delta \mathrm{E})$ and gloss $(\Delta \mathrm{G})$ changes were measured in measured by spectrophotometer Specro Guide Gloss S, fy BYK-Gardner, USA to use CIEL*a*b* regular coordinates. Change of colour is expressed as $\Delta \mathrm{E}$ value calculated according to equation:

$$
\Delta \mathrm{E}=\sqrt{\Delta a^{2}+\Delta b^{2}+\Delta L^{2}}
$$



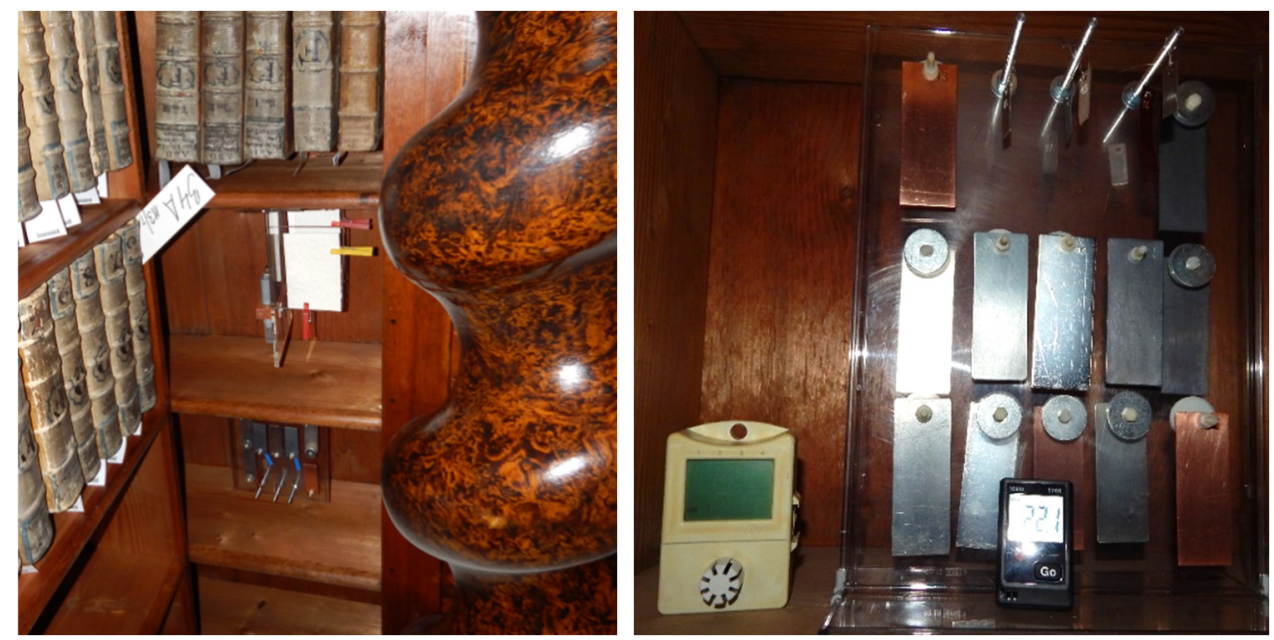

Figure 5: Exposure rack in Baroque library hall.

where $a, b, L$ are coordinates of three-dimensional space for each metallic coupon measured before and after one-year exposure. The appearance of 1 year's exposed coupons is shown in Fig. 6. The most visually evident change of coupons occurred on silver coupons. The colour changes of exposed coupons are given in Table 2. The most intensive changes occurred on zinc and lead on $L$ scale (white/black) and on silver on $b$ scale (yellow/blue).

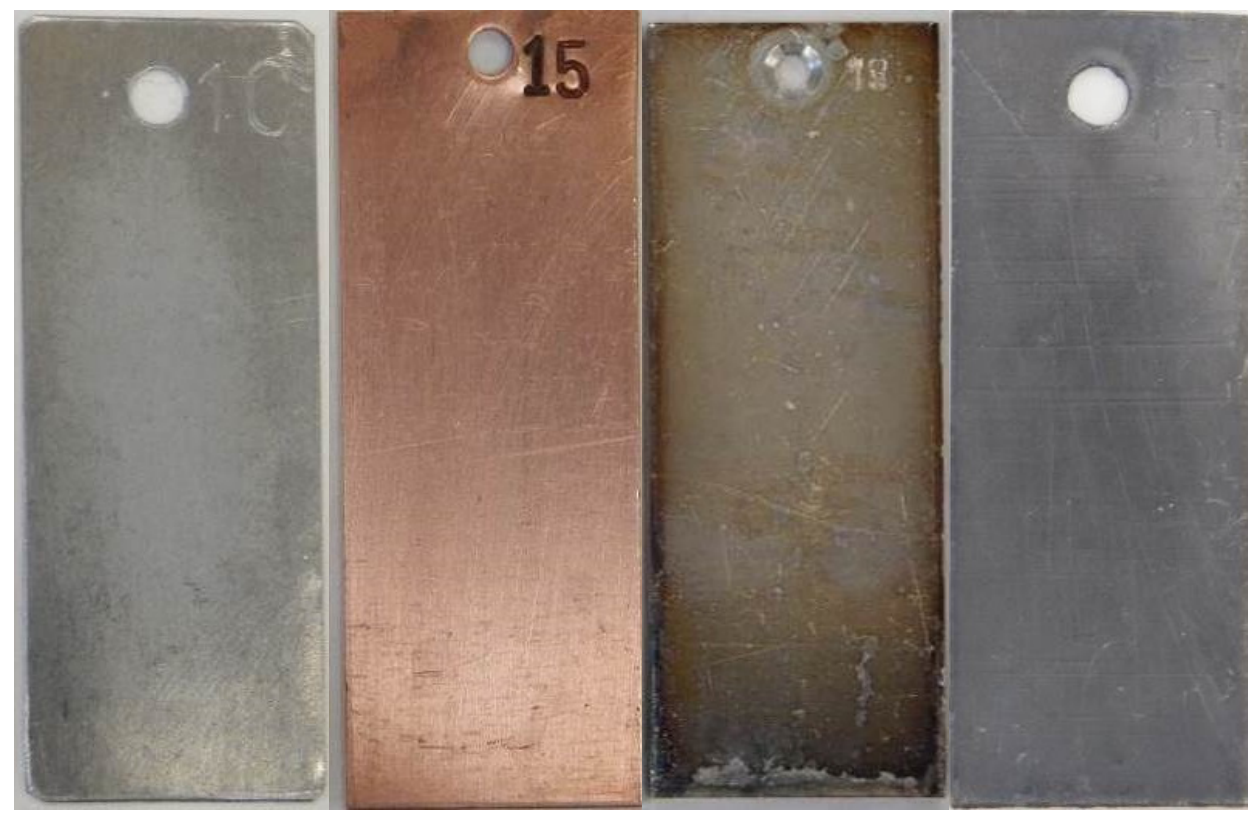

Figure 6: The appearance of exposed coupons (zinc, copper, silver, lead). 
Table 2: Visual changes of exposed coupons.

\begin{tabular}{|l|c|c|c|c|c|}
\hline Material & $\mathrm{L}$ & $\mathrm{A}$ & $\mathrm{b}$ & $\Delta \mathrm{E}$ & $\Delta \mathrm{G}$ \\
\hline Zinc & -13.38 & 0.08 & 1.79 & 13.02 & 89.17 \\
\hline Copper & -0.87 & -0.89 & -0.27 & 1.86 & 25.23 \\
\hline Silver & -3.00 & 1.95 & 6.24 & 7.72 & 27.10 \\
\hline Lead & -21.37 & -0.49 & -1.43 & 21.43 & 6.33 \\
\hline
\end{tabular}

The mass gains were evaluated after exposure by weighting and corrosion mass loss were estimated after removal of corrosion products by interval pickling procedure according to ISO 8407 [11] and by electrolytic cathodic reduction (for $50 \times 50 \mathrm{~mm}$ coupons only) according to ISO 11844 [12]. Values and classification of corrosivity of indoor atmospheres based on rate of mass increase measured and based on corrosion rate measurements by mass loss determination of standard coupons are given in Table 3.

Table 3: Corrosion data of exposed coupons.

\begin{tabular}{|l|c|c|c|c|}
\hline \multirow{2}{*}{ Material } & \multicolumn{2}{|c|}{ Mass increase } & \multicolumn{2}{c|}{ Corrosion rate } \\
\cline { 2 - 5 } & $\left(\mathrm{mg} \cdot \mathrm{m}^{-2} \cdot \mathrm{a}^{-1}\right)$ & $\begin{array}{c}\text { Corrosivity } \\
\text { category }\end{array}$ & $\left(\mathrm{mg} \cdot \mathrm{m}^{-2} \cdot \mathrm{a}^{-1}\right)$ & $\begin{array}{c}\text { Corrosivity } \\
\text { category }\end{array}$ \\
\hline $30 \times 80 \mathrm{~mm}$ coupons & 111.1 & $\mathrm{IC} 2$ & 201.4 & IC2 \\
\hline Zinc & 13.9 & $\mathrm{IC} 1$ & 131.9 & IC2 \\
\hline Copper & -13.9 & - & 83.3 & IC1 \\
\hline Silver & 715.3 & - & $5,645.8$ & - \\
\hline Lead & 75.0 & $\mathrm{IC} 2$ & 61.6 & IC2 \\
\hline $50 \times 50 \mathrm{~mm}$ coupons & -96.7 & - & 216.9 & IC3 \\
\hline Zinc & -57.7 & - & 114.6 & IC2 \\
\hline Copper & 629.1 & - & $1,702.3$ & - \\
\hline Silver & \multicolumn{5}{|l}{} \\
\hline Lead & \multicolumn{5}{|l}{} \\
\hline
\end{tabular}

The results are affected by method of estimation - coupons size, corrosion products' removal, etc. Each exposed metal reacts to specific kinds of pollutants which may be present in indoor environments. Copper corrosion is often associated with chlorides, sulphides, and acidic pollutants such as $\mathrm{NO}_{2}$ and $\mathrm{SO}_{2}$. Silver reacts with sulphides such as carbonyl sulphide $(\mathrm{COS})$ and hydrogen sulphide $\left(\mathrm{H}_{2} \mathrm{~S}\right)$. Lead reacts with organic carbonyl pollutants and acidic pollutants, but the classified intervals proposed in ISO 11844-1 are lower than estimated at Klementinum Baroque library hall. Zinc is also sensitive to organic acid pollutants and it is metal mostly reactive in high humidity.

Although the corrosion layer forming was evident from colour and mass changes the layers were so thin than any analytical methods (EDX, XRD, etc.) cannot be used for their identification.

The corrosion rate of copper, silver and lead was measured by resistive AirCorr sensors in period 09-11/2020 (period with average acetic acid concentration $300 \mu \mathrm{g} \cdot \mathrm{m}^{-3}$ ) too. Courses of corrosion rates measured by sensor is given in Fig. 7 - for copper $0.0014 \mu \mathrm{m} \cdot \mathrm{a}^{-1}$, for silver $0.0062 \mu \mathrm{m} \cdot \mathrm{a}^{-1}$ and for lead $0.0261 \mu \mathrm{m} \cdot \mathrm{a}^{-1}$. The corrosion rate of copper is slightly reduced due to forming of patina layer. The corrosion rate of lead was significantly higher than for other metals which shows the effect of organic acid pollution. 

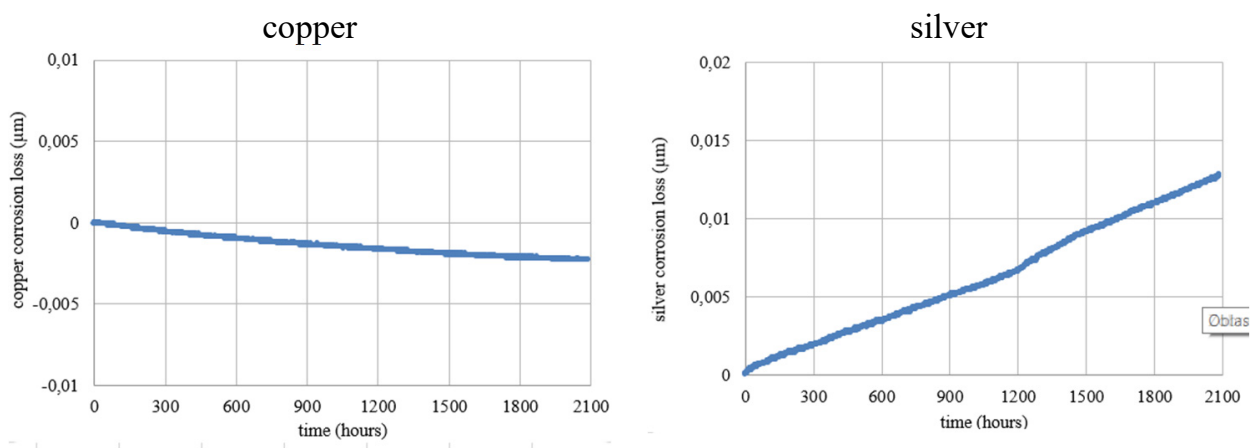

Figure 7: The AirCorr sensors' corrosion loss (copper, silver).

\section{CONCLUSION}

In both storage and display, the processes of corrosion may threaten the stability of metal artefacts. Organic acids, mainly acetic and formic, are known to be significant pollutants in the museum and similar indoor environments. Higher concentrations are usually observed in confined spaces, such as display cases or storage enclosures, due to low air-exchange rates. The Klementinum Baroque library hall is large space, but the exchange of air is reduced as there is limited access to this hall. The library was closed for public since the 1920 s till the year 2000 .

The acetic acid is known to affect metals (particularly lead), calcareous materials (shell, limestone, calcium-rich fossils), soda-rich glass, and cellulose. Examples of deterioration due to acetic acid include the corrosion of lead-rich organ pipes in churches [13], discoloration of pigments [14], and depolymerisation of paper [15]. The acetic acid has been shown to not effect paper lifetime significantly at values below $250 \mu \mathrm{g} \cdot \mathrm{m}^{-3}$ (100 ppb) [16], but in Klementinum Baroque library hall this limit values had been exceeded during the half of year. Bronze and zinc are also affected by organic acids but to a lesser extent [17].

The measurement of their concentration by commercially available simple methods cannot give correct values due to very low concentration and detection limits of these instruments. Passive samplers are more precise and give better values.

Although the values of corrosion mass changes (increasing and loss) depend on used methods (coupons' size, evaluation), in principle the atmospheric indoor corrosivities of Baroque library hall for tested metals are the same. The complex measurement gives information about indoor corrosivity and prevention means which are necessary for longterm protection of exposed culture heritage artefacts.

Results of determination of corrosivity category in 17 localities of culture heritage objects show that lead is the most sensitive metal from others (zinc, copper, silver) [18]. In many exposure localities the yearly corrosion loss $\mathrm{r}_{\text {corr }}$ of lead was higher than maximal value for corrosivity category IC5 according to revised ISO $11844-1\left(1,600 \mathrm{mg} \cdot \mathrm{m}^{-2} \cdot \mathrm{a}^{-1}\right)$, although for other standard metals the corrosivity categories were only IC1 to IC3. Baroque library hall Klementinum belongs between these localities, too.

\section{ACKNOWLEDGEMENT}

This article was created with the support of NAKI Project No. DG18P02OVV050 from the Ministry of Culture of the Czech Republic. 


\section{REFERENCES}

[1] Brimblecombe, P., The composition of museum atmospheres. Atmospheric Environment B, 24, pp. 1-8, 1990.

[2] Tétreault, J., Airborne Pollutants in Museums, Galleries, and Archives: Risk Assessment, Control Strategies, and Preservation Management, Canadian Conservation Institute: Ottawa, 2003.

[3] Balocco, C., Petrone, G., Maggi, O., Pasquariello, G., Albertini, R. \& Pasquarella, C., Indoor microclimate study for cultural heritage protection and preventive conservation in the Palatina Library. Journal of Cultural Heritage, 22, pp. 956-967, 2016.

[4] Saheb, M. \& Dubus, M., Indoor corrosivity in museums and archives assessment: Standards and recommendations. 7th Indoor Air Quality, 2006.

[5] Kreislova, K., New development of indoor corrosivity classification. 11th International Conference Indoor Air Quality in Heritage and Historic Environments, 2014.

[6] Prosek, T. et al., Real-time monitoring of indoor air corrosivity in cultural heritage institutions with metallic electrical resistance sensors. Studies in Conservation, 58(2), pp. 117-128, 2013.

[7] Dubus, M. \& Prosek, T., Standardized assessment of cultural heritage environments by electrical resistance measurement. e-Preservation Science, 9, pp. 67-71, 2012.

[8] Angellini, E. et al., Atmospheric corrosion of facts in museum indoor environments. EUROCORR 2019, 2019.

[9] Lafuente, D., Cano, E., Llorente, I., Crespo, A., Künne, J. \& Schieweck, A., The effects of organic pollutants on metals in museums: Corrosion products, synergistic effects and the influence of climatic parameter. Proceedings of METAL 2013, 2013.

[10] Gibson, L.T. \& Watt, C.M., Acetic and formic acids emitted from wood samples and their effect on selected materials in museum environments. Corrosion Science, 52, pp. 172-178, 2010.

[11] ISO 8407, Corrosion of metals and alloys - Removal of corrosion products from corrosion test specimens. 2020.

[12] ISO 11844-2, Corrosion of metals and alloys - Classification of low corrosivity of indoor atmospheres - Part 2: Determination of corrosion attack in indoor atmospheres.

[13] Niklasson, A. et al., Air pollutant concentrations and atmospheric corrosion of organ pipes in European church environments. Studies in Conservation, 53, pp. 24-40, 2008.

[14] Oikada, T. et al., Volatile organic compounds from wood and their influences on museum artifact materials I. Differences in wood species and analyses of causal substances of deterioration. Journal of Wood Science, 51(4), pp. 363-369, 2005.

[15] Dupont, A.L. \& Tetreault, J., Cellulose degradation in an acetic acid environment. Studies in Conservation, 45(3), pp. 201-210, 2000.

[16] Tennent, N.H. \& Baird, T., The identification of acetate efflorescence on bronze antiquities stored in wooden cabinets. The Conservator, 16, pp. 39-43 and 47, 1992.

[17] Menart, E., de Bruin, G. \& Strlič, M., Effects of $\mathrm{NO}_{2}$ and acetic acid on the stability of historic paper. Cellulose, 21(5), pp. 3701-3713, 2014.

[18] Kreislova, K., Fialova, P., Strachotova, K., Svadlena, J. \& Majtas, D., Indoor corrosivity classification based on lead coupons, in press. 